\title{
Noise Rejection Using Independent Component Analysis and Wiener Filter For Fetal Magnetocardiogram
}

\author{
Y.Sato, K.Kobayashi, K.Nakai*, A.Fukushima*, M.Yoshizawa, and Y.Uchikawa** \\ Graduate School of Engineering Iwate Univ., 4-3-5 Ueda,Morioka,Iwate 020-8551,Japan \\ *Iwate Medical University, 19-1 Uchimaru Morioka Iwate 020-8505,Japan \\ ${ }^{* *}$ School of Science and Engineering,Tokyo Denki Univ., Ishizaka,Hatoyama,Hikigun,Saitama 350-0394,Japan
}

\begin{abstract}
We measured fetal magnetocardiograms (fMCGs) to analyze variability in the heart rate of a fetus. The heart rate variability was calculated from the interval of the $R$ wave peak of fMCGs. However, the fMCGs had a very weak signal that was buried in noise, and noise rejection was necessary. Independent component analysis (ICA) is a useful method of distinguishing signal and noise components. However, it is difficult to separate noise from the signal, when the measured data have a low signal-to-noise ratio. We propose a method that uses a Wiener filter for post processing in ICA. The Wiener filter can reduce the amount of noise present in a signal by comparison with estimates of the required noiseless signal. The required signal in this study was created by measuring the data. The proposed method was evaluated for 15 fMCGs. As a result, the accuracy of $\mathrm{R}$ wave peak detection was improved by using the Wiener filter for post processing in ICA.
\end{abstract}

Key words: Fetal magnetocardiogram, noise rejection, ICA, Wiener filter

\section{胎児心磁図における独立成分分析と Wiener filter を用いたノイズ除去 佐藤嘉輝・小林宏一郎・中居賢司*・福島明宗*・吉澤正人・内川義則** 岩手大学大学院工学研究科, 岩手県盛岡市上田 4-3-5 ( T 020-8551) \\ *岩手医科大学, 岩手県盛岡市内丸 19-1（ T020-8505） \\ **東京電機大学理工学部, 埼玉県比企郡鳩山町石坂（ ₹ 350-0394）}

1. はじめに

従来, 胎児の心臓における電気的活動を計測する胎児心 電図(fECG：fetal electrocardiogram)は，胎脂の影響によ り計測が困難であった．近年，SQUID 磁束計による胎児 心磁図(fMCG:fetal magnetocardiogram)の計測が可能と なり, 胎児の出生前診断など臨床分野への応用が行われて (るる 1),2). 周産期医療の分野における出生前診断では, 胎 児心拍モニタリングにより胎児不整脈の診断と胎児心拍 数変動の解析を行うことで, 先天性心疾患の早期発見が期 待されている. fMCG 計測において測定された信号に対し $\mathrm{R}$ 波ピーク検出を行い, そのピーク間隔から心拍数を算出 することで胎児心拍モニタリングを可能としている.しか し,fMCG は約 $1 \mathrm{pT}$ と微小な信号であるために環境磁気ノ イズや約 10pT の母親の心磁図(mMCG:mother magnetocardiogram)に埋もれた状態で計測される，そこで，計測 信号に対してノイズ除去を行う必要がある.

我々は, これまで独立成分分析(ICA:Independent Component Analysis)を用いて計測信号からノイズを除去し3), 得られた $\mathrm{fMCG}$ から R 波ピーク検出を行ってきた. しか し, ICAのみではノイズ除去が不十分であるため, R 波ピ 一ク検出時に検出エラーが発生することが分かった. そこ で,本研究では fMCGにおける R 波ピーク検出精度の向上 を目指し, ICAによるノイズ除去の後処理として Wiener filter を組み合わせたアルゴリズムを考案し, その有効性 の検討を行った.
2. 方法

\section{1 計測データ}

fMCG 計測は, 直径 $18.6 \mathrm{~mm}$, ベースライン $50 \mathrm{~mm}$ の 一次微分型コイルを $25 \mathrm{~mm}$ 間隔の格子状 $8 \times 8$ に配置した 64 チャンネル SQUID 磁束計 ${ }^{4)}$ を用いて, 磁気シールド ルーム内で行った. 解析したデータはサンプリング周波数 $500 \mathrm{~Hz}$ の 150000 点(300 秒) とした．被験者は，妊娠週数 が 35 40 週における健常な妊婦および健常な胎児各 15 名 である.また MCG と同時に心電図(ECG: electrocardio -gram）を計測した. 本研究で行う MCGおよびECGは, 平成 17 年 4 月 7 日付けで岩手医科大学医学部倫理委員会 の承諾を得ている.

\section{2 ノイズ除去過程}

Fig.1に今回提案した ICA と Wiener filter によるノイ ズ除去過程を示す. ICAの前処理として, 帯域通過フィ ルタ(BPF:Band Pass Filter)によるノイズ除去及び主成 分分析(PCA:Principal Component Analysis)による白色 化を行う. BPF におけるカットオフ周波数は, $5 \mathrm{~Hz} \sim 40 \mathrm{~Hz}$ とした．また，このときPCAによって白色化と同時に情 報の集約が行われるため, 次元の縮約を行う。今回は，次 元縮約によって失われる情報量を考慮し, PCAの結果で ある白色化信号の累積寄与率が $90 \%$ 以上となる次元数を 採用した．次に，ICAによって独立成分を分離するＩCA アルゴリズムには fastICA を用いた ${ }^{5)}$. 分離された独立成 分から胎児心磁図成分を選択し(後述する), 後処理として 
Wiener filter を用いた. Wiener filter は, ICA で分離で きなかったノイズを除去するために用いた．本論文では， 処理後のデータを fMCG Data と呼ぶ.

\section{2 成分選択}

ICA により分離された複数の独立成分には, $\mathrm{mMCG}$, fMCG, 及びノイズ成分がある. 本研究では, 胎児心拍の抽 出を目的とするため, 分離された成分から fMCGを選択 する必要がある，心拍の特徵である QRS 波を含む成分は 容易に抽出可能であるが, $\mathrm{mMCG}$ と $\mathrm{fMCG}$ の判別が困難 な場合がある. そこで, 同時計測した mECG の R 波の出 現時刻（タイミング）を利用し，そのタイミングと同期し た独立成分を $\mathrm{mMCG}$ とし, 同期していなく且つ最も $\mathrm{R}$ 波 ピークが顕著である独立成分を $\mathrm{fMCG}$ として選択する. 以後, このデータを $\mathrm{R}$ 波ピーク検出信号として用いる.

\subsection{Wiener filter}

Fig.2にWiener filterのブロック図と実際に用いた数式 を示す. Wiener filter は，心磁界信号 $\mathrm{x}(\mathrm{t})$ と雑音信号 $\mathrm{v}(\mathrm{t})$ との混合信号である計測信号 $\mathrm{y}(\mathrm{t})$ に対して, 本来計測した い理想的な信号 $\mathrm{d}(\mathrm{t})(\fallingdotseq \mathrm{x}(\mathrm{t}))$ を出力するフィルタである. このフィルタは, 理想信号 $\mathrm{d}(\mathrm{t})$ とフィルタ出力 $\mathrm{z}(\mathrm{t})$ で表さ れる誤差信号 $\mathrm{e}(\mathrm{t})$ の平均自乗誤差を最小化するアルゴリ ズムである。

プログラム上では, コスト関数 Jを最小化するフィルタ 係数 $\mathbf{w}$ を求めることで最適なフィルタを実現している. このとき, $\mathrm{A}$ は $\mathrm{z}(\mathrm{t})$ の自己相関行列であり, $\mathrm{b}$ は $\mathrm{z}(\mathrm{t})$ と $\mathrm{d}(\mathrm{t})$ の相互相関ベクトルである。

Wiener filter は, 1 次元信号における一般的なノイズ除 去方法であるインパルス応答フィルタや加算平均法のよ うに信号からノイズを低減させるのではなく, 理想信号 $\mathrm{d}(\mathrm{t})$ を再現する目的で使用され，ノイズ成分を減衰させる 逆フィルタである. そのため, 理想信号 $\mathrm{d}(\mathrm{t})$ の選択が重要 な要素となる.

\subsection{Wiener filter における理想信号作成}

2.3 で記述したように, Wiener filter を用いる際には理 想信号が必要となる。これが既知であれば問題ないが，心 磁図のように個人差が激しい信号の場合は理想信号が存 在しない. そのため, 理想信号を作成する必要がある.

今回, 測定データにおいて以下の 2 つのパターンから理 想信号を作成し Wiener filterに利用した．各パターンに おける理想信号作成には，2.2において独立成分として抽 出・選択した fMCG を用いている.

I : 全ての計測信号の中で, ICAのみで十分な R 波ピ ーク検出精度が得られ, 且つピーク間隔から算出された心 拍変動の変化率が最も小さい fMCG Data(ICA)

II : 各計測信号において, ICA により分離された fMCG $\operatorname{Data}(\mathrm{ICA})$ (自らの計測信号を用いている)

パターン II において, 計測信号の SN 比が低い場合など に, 計測信号自身からの理想信号作成が困難な場合がある. これは, ICAの分離精度が不十分であるために, fMCG $\operatorname{Data}(\mathrm{ICA})$ が正しく抽出できないために起こる. その場合

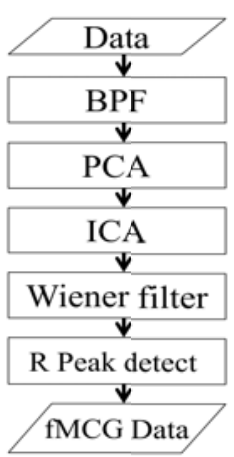

Fig.1 Flow of noise rejection method.

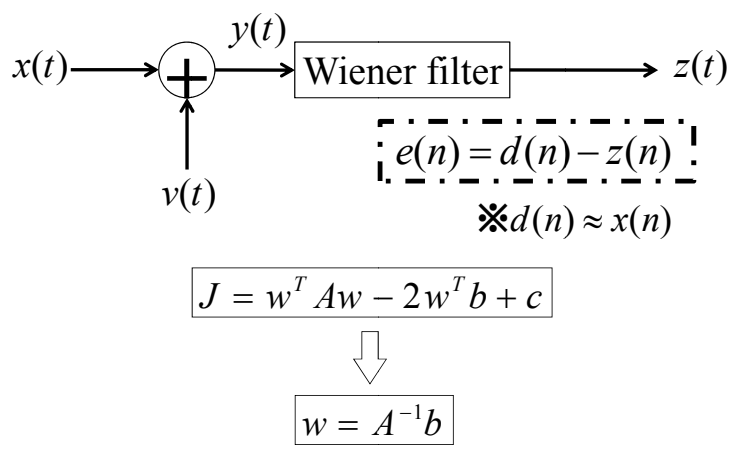

Fig.2 Algorithm for Wiener filter.

には，まずパターン I の Wiener filter を用いて fMCG Data (ICA)におけるノイズ減衰を行う。これにより得られ た fMCG Data(ICA-Wiener( I ))を利用して, 再度理想信 号を作成し，パターンIにおける理想信号とした。また， これらの理想信号の作成にはノイズ除去を目的に加算平 均を用いている.

\section{3.結果}

一例として，Fig.3 に測定データの波形を示し，Fig.4 に ICA によって分離された独立成分の一例を示す. Fig.3 の計測波形では, $450 \mathrm{~ms}, 1000 \mathrm{~ms}, 1600 \mathrm{~ms}$ 付近に数 pT の ピークが現れている.ピークの時間間隔及び信号の強度か ら,このピークは mMCG と判断することができる. Fig.4 の波形では, $400 \mathrm{~ms}, 800 \mathrm{~ms}, 1200 \mathrm{~ms}, 1600 \mathrm{~ms}$ 付近に負の ピークが現れている.この波形は，ピーク間隔から fMCG であると示唆される。しかし， $1100 \mathrm{~ms}, 1700 \mathrm{~ms}$ 付近にも 負のピークが現れていることから，正確に $\mathrm{fMCG}$ の R 波 ピークを検出することが困難である。また，Fig.5にパタ ーン I の場合の理想信号を示す. 加算平均によりノイズが 除去され波形のピークが顕著に現れていることが分かる.

提案方法の有効性を示すため，ICA のみ及び ICA の後 処理として Wiener filter を用いてノイズ除去を行い， R 波ピークの抽出結果を比較した.

\subsection{Wiener filter を用いない場合（ICAのみ）}

ICAのみで処理を行った信号 fMCG Data(ICA)におけ る心拍変動の一例を Fig.6 に示す. 縦軸は R 波ピーク間隔 から算出した心拍変動であり，横軸は経過時間である.

Fig.6 から心拍数が $420 \mathrm{~ms}$ (約 $140 \mathrm{bpm}$ ) 付近を推移してい ることが分かる。また，Fig.6において 100 200s 間に心 
拍数が急激に変化している箇所が見られる. これが, ICA によるノイズ除去では分離できなかったノイズ成分の影 響で発生した R 波ピーク検出エラーである.

3.2 Wiener filter を用いた場合

ICA の後処理としてパターンI の Wiener filter を用い た信号 fMCG Data(ICA-Wiener( I ))における心拍変動を Fig.7 に示す. Fig.6 と比較してみると 100 200s で確認 されていた心拍数の急激な変化が無くなっていることが 分かる.これは, R 波ピーク抽出エラーの減少によるもの である。

また, パターン I では十分な結果が得られなかった場合 の一例を Fig.8 10 に示す. Fig.8は, fMCG Data(ICA) における心拍変動であり, Fig.9 は, パターン I の理想信 号を用いた fMCG Data(ICA-Wiener( I ))における心拍変 動であり, Fig.10 は,パターン II の理想信号を用いた fMCG Data(ICA-Wiener(II))における心拍変動である. Fig.8か ら, ICAのみではノイズ除去が不十分でありピーク検出 が正しく行われていないことが分かる. Fig.9 では Fig.8 に比ベてパターン I の Wiener filter によってピーク検出 精度が改善されていることが分かる. しかし，この場合で も検出エラーが数多く発生している. Fig.10を見ると, パターン I の結果よりも更にピーク検出精度が向上して おり, 検出エラー数が減少していることが分かる.

\section{4.考察}

始めに, 提案手法によって得られた $\mathrm{R}$ 波ピーク検出率 改善結果の妥当性について定量的評価を行った. 以下にそ の方法及び結果を示す。

まず, ICA のみによる信号分離で十分な SN 比が得られ, 且つ検出エラーを生じなかった fMCG Data(ICA)の R 波 ピーク間隔を真值とする. 次に, 同データのノイズ成分の みを増加させた信号を作成する。ノイズ成分の増加には PCA の逆処理を用いた。累積寄与率が 90\%を超えた後の 主成分を全てノイズと判断し，定数倍(10,50,100, 200 倍) した後, PCAの逆処理により源信号に乗算した。 ノイズ 成分を増加させたデータに対して, 提案手法を用いてピー ク検出精度を改善した後, $\mathrm{R}$ 波ピーク間隔を算出し真值と の差を求めた。

提案手法の結果における $\mathrm{R}$ 波ピーク間隔と真值との一 致率を Fig.11に示す.ノイズ成分を 200 倍にした場合で も，97\%の高い一致率を示した。 これにより，提案手法に よる結果が妥当であることが示唆される.

この結果を踏まえ, 今回の信号処理結果について, 以下 の評価方法により検討を行った。

\section{1 評価方法}

検出した R 波ピーク間隔から算出した胎児心拍変動に 対して, 下記の場合を検出エラーとし, その個数から精度 を評価した。

(1)胎児正常整脈(120 160bpm)外の場合

(2)直前の瞬時心拍からの変化率が $5 \%$ 以上である場合

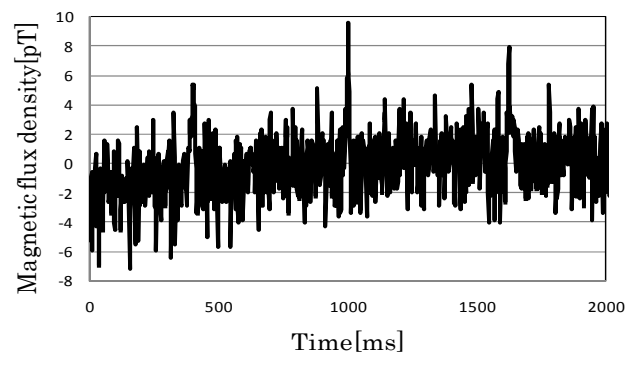

Fig.3 Measured data.

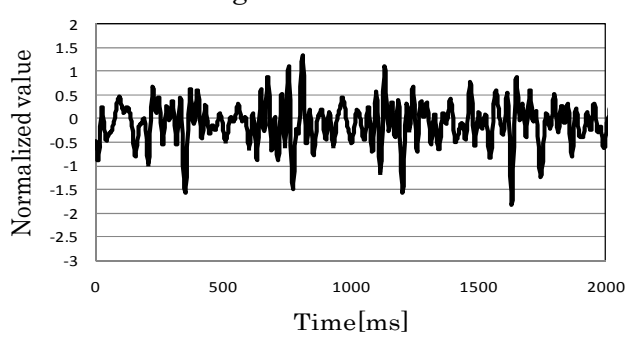

Fig.4 Signal data separated by ICA.

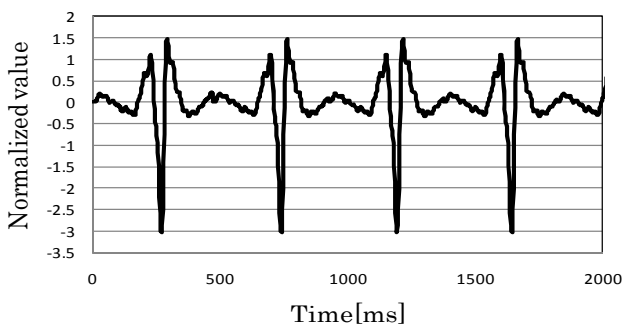

Fig.5 Required noiseless signal.

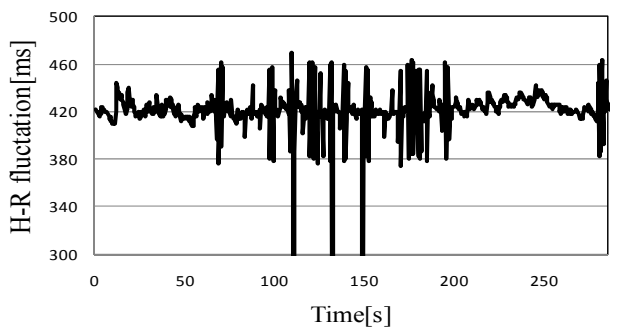

Fig.6 Heart rate fluctuations calculated from fMCG data (ICA and Subject A).

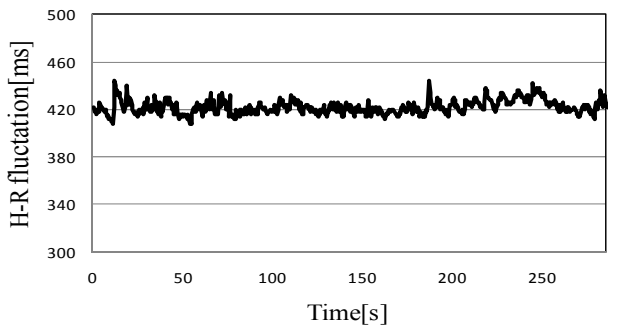

Fig.7 Heart rate fluctuations calculated from fMCG data (ICA-Wiener ( I ) and Subject A).

\section{2 評価結果}

Fig.12に，全被験者における fMCG Data(ICA)で発生 した $\mathrm{R}$ 波ピーク検出エラーの総数を $100 \%$ とした場合の fMCG Data(ICA), fMCG Data(ICA-Wiener( I )), fMCG Data(ICA-Wiener( II ))における誤検出率および各データ による標準偏差を示す.fMCG Data(ICA-Wiener（ I )) と fMCG Data(ICA-Wiener (II))の誤検出率がそれぞれ 38\% と $14 \%$ となり，Wiener filterにより誤検出率が改善され 
た. また, 各データによるばらつきも小さくなっているこ とが分かる.このことから, 提案手法の中でも計測データ 自身から理想信号を作成した ICA-Wiener (II)の誤検出率 が最も低くなることが分かった。

以上のことから, ICA を用いた fMCGのノイズ除去に おいて，後処理として Wiener filter が有効であることが 示された. また, 今回解析対象とした心拍変動には個人差 があるため，一意に理想信号を定めることはできない。こ の個人差を考慮して理想信号を作成するための方法とし て, パターンIの方法を提案した. ICA 後の fMCG Data (ICA)において, 残留しているノイズの影響により $\mathrm{R}$ 波ピ 一ク検出エラーが発生し, 直接理想信号が作成できない場 合には，一度パターン I の Wiener filter を用いて R 波ピ 一ク検出エラーを減少させた。 その後, 得られた $\mathrm{fMCG}$ Data(ICA-Wiener( I ))を利用して再度理想信号を作成し， パターンII として用いた.この方法によりパターン I の理 想信号を用いた場合よりも検出ミスを減少させることが できた. 以上のことから, Wiener filter においては測定 信号にマッチした理想信号を作成する方法が重要な意味 を持つことが分かった，そして今回提案した方法は，この 問題に対して有効であると示唆される。

\section{5.まとめ}

胎児心磁図における心拍変動を求める際に必要となる $\mathrm{R}$ 波ピーク検出において,ICA によるノイズ除去の後処理 として新たに Wiener filter を用いることで, ノイズ除去 精度の向上を行った。

このアルゴリズムの有効性を, 実際の計測データを用い て検証した。 また，Wiener filter における理想信号の作 成にあたり，2つのパターンを用いた。この提案手法によ り測定信号に適した理想信号を作成することが可能とな った.

以上から, 今回提案した方法により, R 波ピーク検出ミ スを減少させることが可能となった.

謝辞 本研究の一部は日本学術振興会科学研究費 基盤研 究（B）（21300158）および 基盤研究（C）（21592105） の助成の下で行った.

\section{References}

1) A.Kandori, T.Miyashita, K.Tsukada, T.Hosono, Y.Chiba, H.Horigome, S.Shigematsu, M.Asaka :Physiological Measurement,22-2,377(2001)

2) A.Fukushima,K.Nakai,M.Itho,H.Horigome,A.Suwabe, K. Tohyama,K.Kobayashi,M.Yoshizawa,T.Sugiyama, Clinical Medicine:Cardiology,2,33,(2008)

3) K.Kobayashi,K.Oyamada,M.Yoshizawa,Y.Uchikawa:Jour nal of Magnetics Society of Japan,34,2,156(2010)

4) M.Yoshizawa,D.F.He,K.Nakai,K.Kobayashi,Y.Nakamura, M.Yaegashi, M.Ito, H. Yashiro, M.Daibo, T. Simizu, Y. Uchhikawa, K. Noto:Application of squids in the Iwate create project, Physica $C, 426,1572,(2005)$

5) A. Hyvarinen, J. Karhunen, E. Oja : Independent Component Analysis, (in Japanese) ,(Tokyodenkidaigaku Shuppankyoku,Tokyo,2005)

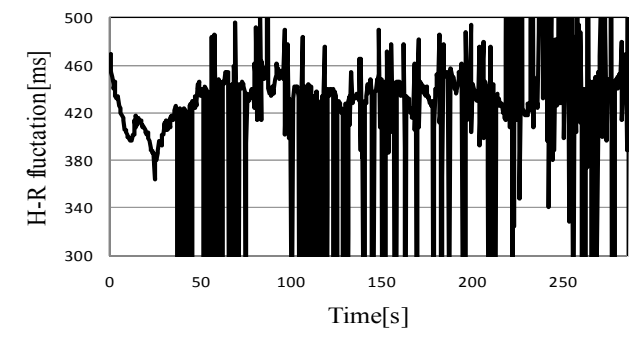

Fig. 8 Heart rate fluctuations calculated from fMCG data (ICA and Subject B).

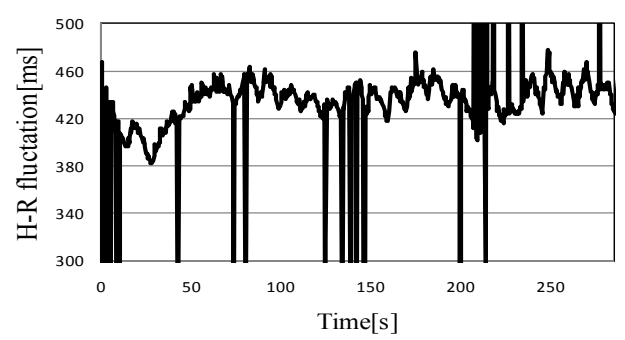

Fig.9 Heart rate fluctuations calculated from fMCG data (ICA-Wiener ( I ) and Subject B).

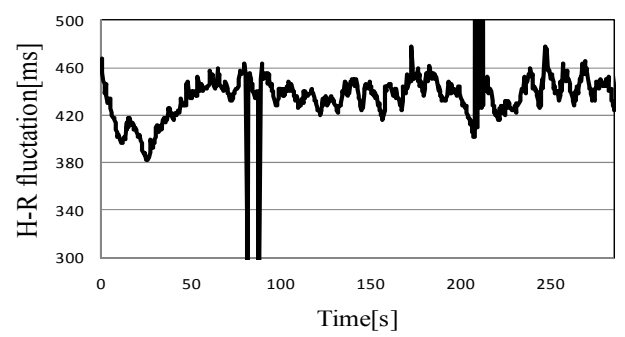

Fig.10 Heart rate fluctuations calculated from fMCG data (ICA-Wiener (II) and Subject B).

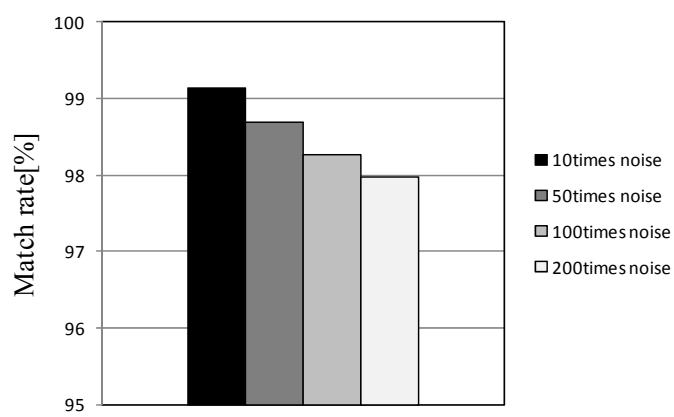

Fig.11 Match rate detection of $\mathrm{R}$ wave peak.

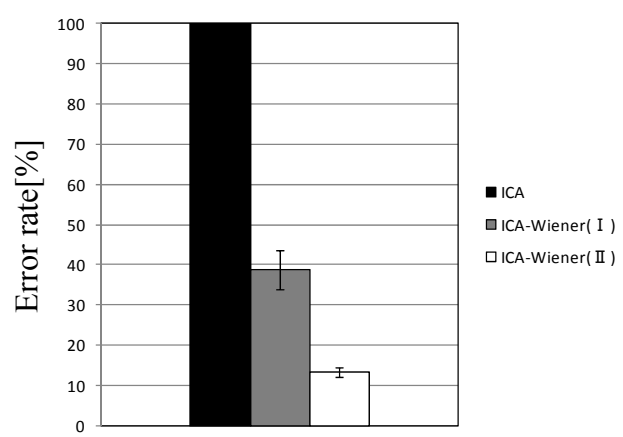

Fig.12 Error rate in detection of $\mathrm{R}$ wave peak.

2010 年 10 月 18 日受理, 2011 年 3 月 24 日採録 